\title{
BLOCKCHAIN TECHNOLOGY ADOPTION IN SUPPLY CHANGE MANAGEMENT: TWO THEORETICAL PERSPECTIVES
}

\author{
Jennifer L. Breese, Penn State University,jzb545@psu.edu \\ Sung-Jin Park, Indiana University South Bend, sungipar@iusb.edu \\ Ganesh Vaidyanathan, Roosevelt University, gvaidyanathan@roosevelt.edu
}

\begin{abstract}
Security through decentralization and reliability are the main values that Blockchain technology brings to supply chain management. The increased security in the form of the shared ledger could potentially eliminate a myriad of audits required by systems and processes in supply chain management. This paper focuses on two theories to explain two key supply chain management factors including supplier customization and confidential information sharing. Smart Contracts are used to explain the security of Blockchains in supplier customization. Trust, cooperation, and reverse logistics are further explored to explain how security in Blockchain can be used for information sharing.
\end{abstract}

Keywords: Blockchain, Supply Chain, Supply Chain Management (SCM), Smart Contracts, Trust, Reverse Logistics, Security

\section{INTRODUCTION}

Blockchain technology is being touted as the panacea to all that is lacking in security, cost, and simplicity for industries ranging from Financial, Supply Chain, Healthcare, and beyond. The Blockchain is becoming a trusted intermediary; industries are looking to embrace disruption through adoption of new technologies (Koul, 2018). Tapscott and Tapscott (2016) boldly state that Blockchains have the potential to revolutionize the world economy.

This paper will explore the potential shift to Blockchain technology as a primary information exchange protocol for supply chain overtaking the current dominate protocols established by the Supply Chain between trading partners. The Blockchain is an incorruptible digital ledger of economic transactions programmed to record not just financial transactions but virtually everything of value; additional trust through the secure transaction is a key element (Bambara \& Allen, 2019; Tapscott \& Tapscott, 2016). The name Blockchain was coined for the way the technology stores transaction data - in blocks that are linked together to form a chain. Blocks record and confirm the time and sequence of transactions that are logged within a discrete network governed by rules agreed on a priori by the network participants. Each block contains a hash, a digital fingerprint. The hash of the previous block is linked to the next and this arrangement prevents any block from being altered and is immutable. In summary, the Blockchain is not a replacement for business process, transaction processing, or a database it serves as a database for recording transactions. The essential value of the Blockchain is a decentralized, trustable, collectively maintained, reliable and open source database (Bambara \& Allen, 2019; Tapscott \& Tapscott, 2016; Werbach, 2018).

Blockchain research to date has been focused on the use case to support bitcoin described by Lo and Wang (2014) as the dominant virtual currency. Research is limited to the adoption of Blockchain in Supply Chain and the potential for both customer and company benefits. The implication of mass adoption of the technology could not only disrupt the industry standard protocol for information transfer but also provide a value proposition influencing consumer behavior. The element of the technology, which provides differentiating factors of transaction cost in Transaction Cost Economics (TCE) theory and trust as addressed in Social Exchange Theory (SET) as constructs focus on smart contract code automating actions based on scenarios developed or selected in the overall exchange process. 


\section{THEORY}

While much attention focuses on simply disruption of new technologies on an industry, we draw two different theoretical perspectives to explain the possible invasion of Blockchain technology in the supply chain. Transaction Cost Economics (TCE) theory involves a transaction cost, a cost incurred in making an economic exchange, for example; costs required to come to an acceptable agreement with the other party to the transaction, drawing up an appropriate contract, etc.

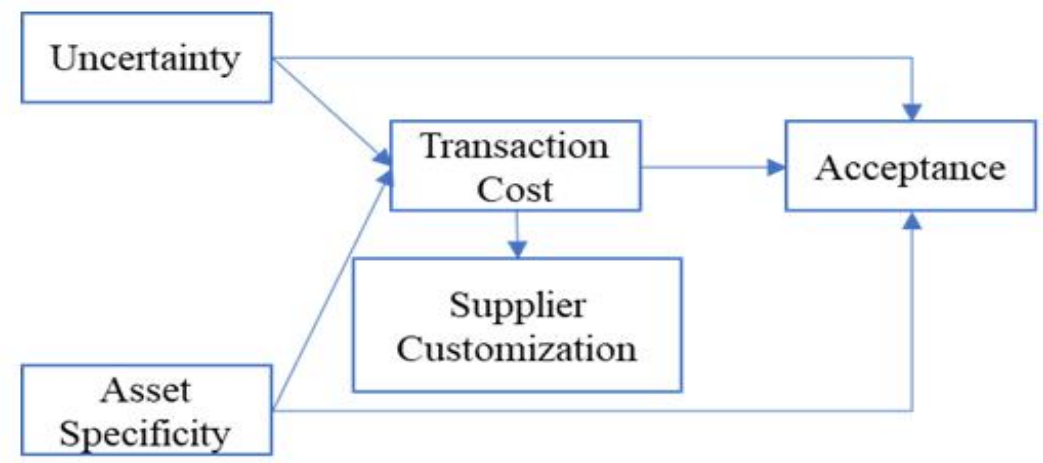

Figure 1. Blockchain Transaction Cost Economics in SCM

The cost of establishing a supposedly tamper-proof contract, and the costs of monitoring and enforcing the implementation of the contract is a crucial factor in supply chain management. This is shown in Figure 1, which was adopted from Liang and Huang (1998). Such coordination costs are defined as the costs of "all the information processing necessary to coordinate the work of people and machines that perform the primary processes," whereas production costs include the costs incurred from "the physical or other primary processes necessary to create and distribute the goods or services being produced" (Malone, Yates \& Benjamin, 1987, p. 485). According to Transaction Cost Economics, asset specificity is a key driver of transaction costs and the relationship between supply chain partners (Devaraj, Vaidyanathan, \& Mishra, 2012). Asset specificity has emerged as a reliable and consistent predictor of interorganizational relationships and sourcing decisions (Poppo \& Zenger, 1998). Asset specificity is related to alternative uses of the asset involved in the transaction, and it is measured by the lack of standardization. In our context, asset specificity can be operationalized as supplier customization. The extent to which a supplier has customized its assets, processes, and tools to meet a buyer's requirements is a significant indicator of its commitment to meet the idiosyncratic requirements of the buyer and is a key economic factor (Devaraj, Vaidyanathan, \& Mishra, 2012).

Social Exchange Theory (SET) culminates economics, psychology, and sociology. The theory was developed to understand the social behavior of humans in economic undertakings. Although social exchange theory was originally proposed in the context of interpersonal relationships, many of its propositions are well suited for analyzing the interorganizational exchange relationship between two firms (Son, Narasimhan, \& Riggins, 2005). According to SET, pure economic factors are insufficient to explain inter-organizational relationships, and social factors inform why firms engage in extensive coordination in the interests of maintaining long term relationships (Devaraj, Vaidyanathan, \& Mishra, 2012). In our context, we have conceptualized trust as the key social factor that may influence the onset of Blockchain technology in supply chain management as shown in Figure 2, adopted from Son, Narasimhan, \& Riggins, 2005). 


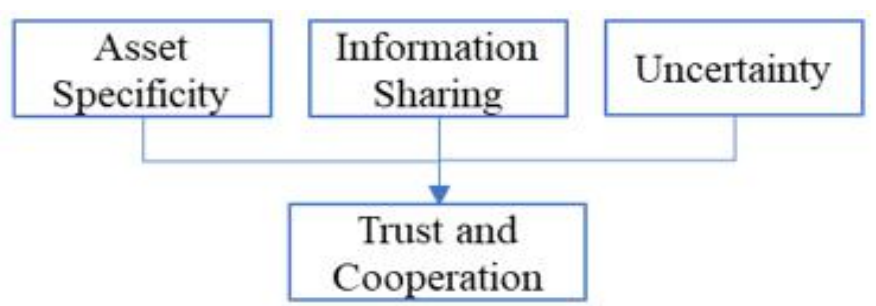

Figure 2. Blockchain Socio-Economic Theory in SCM

Scholars have acknowledged communication as an essential factor in supply chain management and suggested product customization and information sharing constitute key characteristics in e-procurement processes (Chen, Paulraj, \& Lado, 2004; Doney \& Cannon, 1997; Muffato \& Payaro, 2004; Subramani, 2004). Trust, "a firm's belief that another company will perform actions resulting in positive outcomes for the firm, as well as not take unexpected actions that would result in negative outcomes for the firm" (Anderson, \& Narus, 1990, p, 45) are important aspects of interfirm exchange relationships. Trust can be viewed as one party's confidence in the reliability and integrity of an exchange partner (Morgan \& Hunt, 1994).

\section{THEORETICAL PERSPECTIVES OF KEY SUPPLY CHAIN MANAGEMENT FACTORS}

Doney and Cannon (1997) argue supplier customization and confidential information sharing are among the two most important characteristics in inter-organizational relationships and the coordination of supply chain activities. Supplier customization refers to the dedicated assets such as tools and equipment and custom-made processes that a supplier devotes to the buyer firm. The customization efforts are indicative of the willingness of the supplier to conform to the needs of the buyer. Supplier customization includes initiatives on the part of the supplier to acquire specialized equipment in order to manufacture customized and tailored products and to modify internal processes to conform to the needs of the buyer (Doney \& Cannon, 1997). From a transaction costs economics perspective, such customization initiatives can be considered as asset specificity. Because procedures, assets, and tools are customized to a specific buyer, their economic value and salvage potential are considerably less if they are switched to alternative transactions. Thus, asset specificity tends to promote supplier-buyer relationship on economic grounds. From the buyer's standpoint, supplier customization allows modifying the supply of products rapidly in response to changing customer needs. For instance, Hsieh, Chiu, \& Hsu (2008) claim that market-oriented suppliers from Taiwan emphasize the customization of their processes to satisfy their customers. In the consumer electronics sector, for example, buyers welcome flexibility because of their need for a high level of customization and frequent changes in product mix and delivery. Supplier arrangements and customizations enable buyer firms to appropriately structure inter-organizational information flows and coordinate procurement processes, thereby reducing the effort necessary for resolving external uncertainties (Gosain, Malhotra, \& El Sawy, 2005). In general, customization can be described from two perspectives including a process perspective and a content perspective. The process perspective concerns how customized products are developed (Fettermann \& Echeveste, 2014). The content perspective focuses on different aspects of the actual customization such as if it is related to whether the properties of the product are unique to a particular customer order or whether the product only has standard properties that are the same irrespective of the customer (Lampel \& Mintzberg, 1996). Kakela and Wikner (2018) define individualized customization as a customized solution that is defined after commitment to the customer with no predefined solutions as options. This is different from modularization and mass customization where suppliers design or engineer possible solutions in advance (Fogliatto, Da Silveira, \& Borenstein, 2012).

Social exchange scholars present various social rationales for why buyer and supplier partnerships might continue to sustain a relationship in contrast to the economic rationale of transaction cost economics. In this theory, supply chain partners will engage in information sharing if it helps to foster their relationship. The history of a relationship is a significant driver of commitment to a relationship. The length of successful collaboration between two firms will determine the likelihood to engage in activities such as information sharing that benefit the relationship (Seabright, Levinthal, \& Fichman, 1992). Moreover, reputation is an important attribute in supply chain relationships (Kollock, 1994). In a systematic procurement arrangement where regular transactions are expected to occur on a long-term basis 


\section{Issues in Information Systems \\ Volume 20, Issue 2, pp. 140-150, 2019}

via negotiated contracts with qualified suppliers, organized information transfer between the trading partners may be crucial to achieving efficiency in recurring transactions (Kim, Umanath, \& Kim, 2005). The information sharing capabilities include the integration of the systems, decisions, and processes (Hsu, Kannan, Tan, \& Leong, 2008). The availability of information allows firms to sense the need for change in their current process configuration and to develop mechanisms for dealing with change. This is particularly useful for supplier customization efforts as firms that exchange information with suppliers extensively can respond to demand changes with agility. Frequent information exchange between a firm and its suppliers encourages the firm to share both tactical information (e.g., engineering change orders, reject rates, inventory positions), and strategic information (e.g., product roadmap, demand forecast, cost curves) with suppliers (Devaraj, Vaidyanathan, \& Mishra, 2012). Such detailed information sharing enables the buyer and its suppliers to coordinate their design efforts, production plans, and shipping schedules more effectively. Cachon and Fisher (2000) found that the sharing of real-time demand information provides significant operational improvements. In addition to providing operational savings, firms have come to realize that sharing information with business partners can facilitate meeting customers' needs in a timely manner. The exchange of information with suppliers enables buyer firms to communicate customer requirements to suppliers, and aids in procuring parts and components that are required to satisfy changing customer requirements.

Young-Ybarra and Wiersema (1999) state trust between buyers and suppliers will have a positive impact on the desire and ability of partners to adjust to changing environmental demands. Higher levels of trust in business partners indicate that an organization believes in the competence or expertise of its partners to deliver. The trusting organization also expects that the trusted party will not take advantage of the contractual conditions by willful exploitation (YoungYbarra \& Wiersema, 1999). While increased information sharing enables suppliers and buyers to be flexible to customer demands (Rosenzweig, Roth, \& Dean, 2003), Handfield and Bechtel (2002) argue that firms are more willing to be responsive to partners who have exhibited trustworthiness. The cooperative behavior facilitated by higher trust enables firms to survive greater stress and display adaptability under changing conditions (Doz, 1996; Lorenz, 1988). Higher trust between partners lowers transactions risks and information abuse online by partners and increases the chances that contractual terms will be honored online, and hence is likely to enhance the relationship between information sharing and flexibilities in supply chain management.

In general, customization costs will reduce the profits of suppliers. Engaging in close communication based on collaborative relationships between buyers and suppliers will promote information-sharing. Information-sharing between buyers and suppliers could reduce customization costs (Nakagawa \& Song, 2016). We use smart contracts to explain the security of Blockchains in supplier customization. Trust, cooperation, and reverse logistics are explored to explain how the security in Blockchain can be used for information sharing and reducing transaction costs.

\section{BLOCKCHAIN IMPLICATION ON SUPPLY CHAIN MANAGEMENT}

Based on the above theoretical perspectives of key supply chain management factors, we will develop implications of Blockchain technology in supply chain management. In a recent survey of almost 3,000 global C-suite executives, IBM found 33 percent of organizations, on average, across all industries and regions are already considering or actively engaged with Blockchains (IBM, 2017). The Explorers, organizations that are already experimenting with, piloting or implementing Blockchains are finding that Blockchain technology is likely to radically change how their organizations operate, generate revenues and respond to customers, partners and competitors alike (IBM, 2017).

In this theoretical exploration, we explore three attributes of supply chain management and their implications with Blockchain technology including supply chain contracts, trust in supply chains, and reverse logistics.

\section{Supply Chain Contracts}

Mentzer, DeWitt, Keebler, Min, Nix, Smith, and Zacharias (2001, pg. 6) define supply chain management as activities "to integrate and manage the sourcing, flow, and control of materials using a total systems perspective across multiple functions and multiple tiers of suppliers". When supply chain management intends to provide coordination and facilitate collaboration between buyers and suppliers with respect to the flows of goods and services and corresponding financial resource, it is eventually summarized into enforceable contracts between the two parties. While the trust and the enforceability of the contracts form the foundation of effective supply chain management, information asymmetry 


\section{Issues in Information Systems}

Volume 20, Issue 2, pp. 140-150, 2019

between the parties and the related agency costs for monitoring and assurance function require significant resource from both parties (Lajili \& Mahoney 2006). Notably, the economic burden of transaction costs through supply chains escalates as the supply chain becomes longer, more complex by involving multiple tiers of suppliers, and more global.

Blockchain technology as an enabler of smart contracts can ameliorate the concern of increasing transaction costs along the supply chain. Initially, Szabo (1996) developed the notion of a smart contract as the digital promises and protocols where the parties execute on them (Bambara \& Allen, 2018). These contracts become a social form of trust through transparency fulfilling a historical model of a social contract without the potential or need for enforcement by a government or a certified authority (Szabo, 1996; Bandzar 2016). Once supplier arrangements and customizations are in place, buyer firms can use Blockchain technologies effectively to procure input materials that would serve customer requirements better. The rich communication enabled by Blockchain allows firms to transmit features, specifications, and requirements much more succinctly and accurately to suppliers.

Smart contracts can be used to optimize the global supply chain for buyers, suppliers, and other stakeholders in the supply chain. Suppliers and buyers normally have different and conflicting objectives. For instance, suppliers want buyers to commit themselves to purchase large quantities of products in stable volumes with flexible delivery dates. Conversely, buyers need to be flexible to their customers' needs and changing demands. The difficulty with global optimization is that it requires firms to surrender decision-making power to an unbiased decision maker. Using Blockchain technology, buyers and suppliers can design supply contracts to maximize profit on the supply chain with more visibility into demand, inventory and upstream/downstream operations through a trusted and secure network. Additionally, interactions and agreements can be saved automatically with a traceable record.

One critical element of supply chain contracts is related to the money flows through the supply chain, i.e., supply chain finance. Suppliers often sell their goods and services to their buyers on credit rather than requesting immediate cash payment. When the suppliers extend trade credits to the buyers in the form of accounts receivable, they are exposing themselves to the buyer's demand risk and default risk (Jing \& Seidmann, 2014; Yang \& Birge, 2018). Essentially, the supply chain relationship between a buyer and a supplier is grounded in the financing contracts stipulating the terms of trade finance, which enables the buyer finances its purchase of goods and services from the supplier. In the United States, the nonfinancial firms in aggregate have extended about 210 billion dollar worth of trade credit in 2017, almost equal amount of external financing to their bank loans (Federal Reserve, 2018). Through the process of extending and collecting trade credit, the supplier's working capital can inflate unnecessarily and the cash flow problem may occur, which threatens the effectiveness of the buyer-supplier relationship (Fabbri \& Klapper 2016). As such, the supply chain financing mechanism draws attention from all stakeholders along the supply chain.

Historically, factoring and the sale of accounts receivable to a financial institution was a common method of mitigating the risk from trade credit (Mian \& Smith, 1992). While the involvement of third-party financial institution in the supply chain relationship is costly, a large factor with established credit-risk evaluation teams and procedures can improve the overall efficiency of the supply chain by managing the trade credits more efficiently than an individual supplier's own management of accounts receivable. However, when a supplier is relatively smaller and has sub-par credit quality, the financing costs of the factoring can be substantial, especially for the recourse factoring of the receivables from multiple buyers. In particular, as supply chains get longer and more global, information collection and credit-risk assessment of a complex portfolio of various suppliers becomes more challenging and incurs larger costs associated with the trade credits and factoring.

More recently, a new form of supply chain financing mechanism has emerged, often referred to as reverse factoring to reduce the transaction costs arising from supply chain financing. Different from the traditional factoring, the reverse factoring is initiated by a large buyer to leverage its higher credit quality to lower the suppliers' trade financing costs while the buyer's payments are continued to be delayed. For instance, Wal-Mart has been maintaining a reverse factoring platform with thousands of suppliers, called the Supplier Alliance Program, since 2013. When Wal-Mart's purchase order is placed and a supplier delivers the goods, the invoice for the transaction is submitted by the supplier to the reverse factoring platform backed by a group of banks including Wells Fargo and Citi Bank. Upon the approval of the invoice by Wal-Mart, the funding bank can enable the platform to remit the corresponding payment to the supplier after verifying all documents. 


\section{Issues in Information Systems}

Volume 20, Issue 2, pp. 140-150, 2019

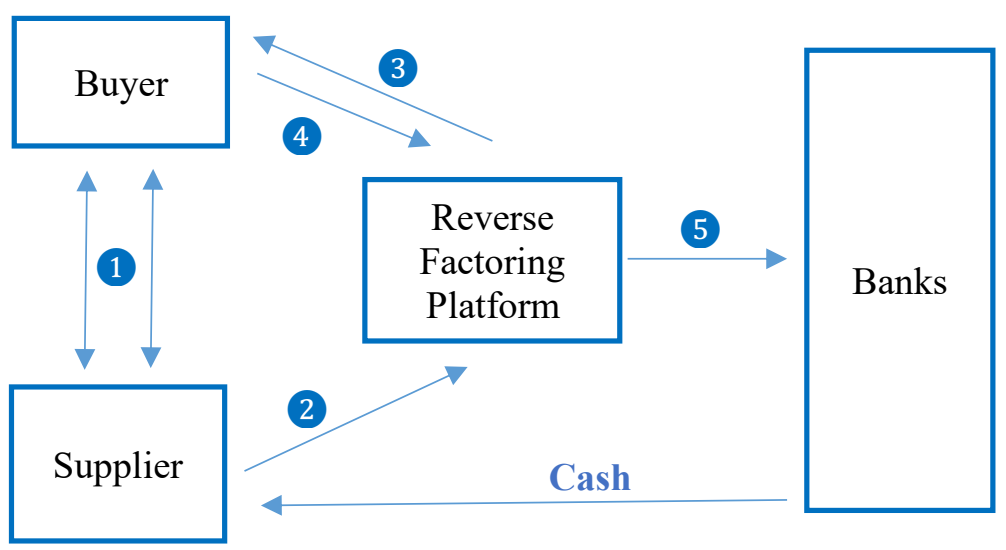

Figure 3. Information Flow of Reverse Factoring

For any supply chain financing mechanism, including both traditional factoring and reverse factoring, the most critical determinant of financing cost is related to assuring the integrity of the transaction information, i.e., information asymmetry. When a supplier is young and small, and accordingly, lacking track record and reputation, supply chain financiers (factors) may charge prohibitively high financing costs to protect themselves from unfathomable credit risk. Even for reverse factoring, the collection and verification of transaction information may increase overall financing costs and delay the remittance of payments to the supplier. There is a Federal warning that the fraud related to Letter of Credit, one of the most commonly used supply chain payment guarantees, often occurs when the transaction documents are tampered (FBI, 2019) To the extent that Blockchain technology enables the irreversibility of trade records through peer-to-peer transmissions along a global supply chain (Kokina, Mancha, \& Pachamanova, 2017; Tapscott \& Tapscott, 2017), monetary and nonmonetary transaction costs related to the operation of a complex web of information exchange would be reduced and the overall effectiveness of the supply chain shall be strengthened.

\section{Trust}

IBM (2017) found that six in ten of the organizations who have started using Blockchain feel that the technology creates trust and transparency in both data and transactions. Data recorded to a Blockchain can verify that products are maintained according to specifications. For example, Blockchain can verify that wine in transit was stored at the proper temperature and humidity condition. As goods in transit clear customs and ports, organizations can be made aware of their location in real time. Such stored data can dynamically optimize supply chains.

Blockchain provides unique technological qualities, such as immutability, automaticity, pseudonymity, and irreversibility, which in turn may result in unparalleled reliability, transparency and efficiency in the supply chain (Treiblmaier, 2018). Maersk, A pioneer in the execution of logistics, is one of the biggest containers' carriers in the world uses a Blockchain solution to track their containers and paperwork for customs. This technology negates the possibility of fraud; if technology solutions are carefully carved an overall conservative industry could be swayed toward a shift in technology (Hackius \& Petersen, 2017).

Borkovich and Breese (2016) further developed Batteau (2010) who described societies as complex webs of trust, mistrust, and disinformation among groups, individuals, and institutions learned over years of interaction. There exists a fervent crisis of trust extending through all organizations and industries (Werbach, 2018). Borkovich and BreeseVitelli (2014) leaned on the underpinnings of Hofstede's (1980) cultural dimensions research; stating trust can be described in terms of layers of close familial relations extending outward like layers of an onion through colleagues, an organization, and society more broadly. Empirical research by House, Hanges, Javidan, Dorfman, and Gupta, (2004) on trust factors and their interrelationships based on cultural influences resulted in findings on trust as a cornerstone in transactions. In economic terms, trust relates to the reduced transaction costs and monitoring transactions allowing for flexibility in a relationship (Werbach, 2018). 
Trusted relationships in this manner may eliminate the need for regulations by a broader entity and place in in the hands of the transactional players and the community more broadly (Casey and Paul, 2018). Trust in the overall framework described has multiple aspects in this paper; relational, contractual, shared ledger, and overall security.

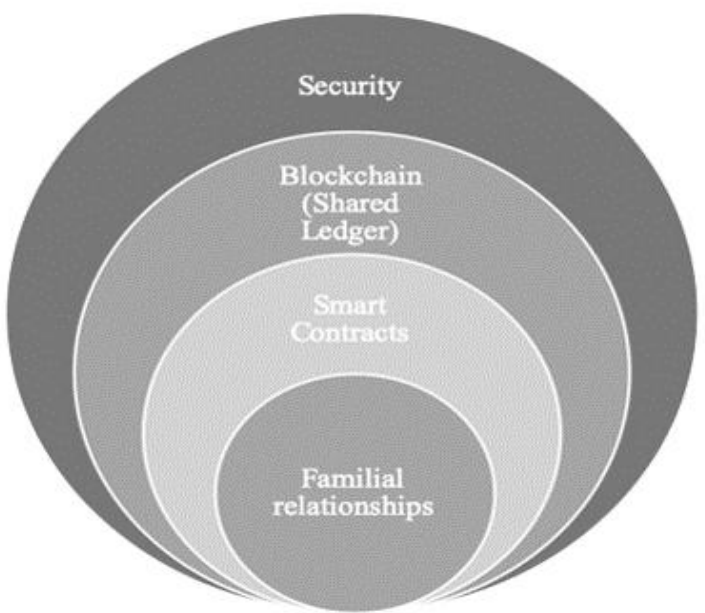

Figure 4. Trust Relationships

\section{Reverse Logistics}

Reverse logistics and their associated activities result in additional costs in the supply chain when compared to forward logistics regardless of the additional potential associated revenue (John, Sridharan, Kumar, 2018). The forward chain involves traditional conditions purchasing from suppliers, producing products, and distribution to end customers (Tombido, Louw, van Eeden, 2018). Simply stated, reverse logistics is anything that goes the opposite way of the traditional forward supply chain in the form of returns (Le Blanc, 2006). Reverse logistics can have varying levels of difficulty with associated costs based on the products involved and their use (Guide \& Wassenhove, 2009). John et al. (2018) and other similar research (John, \& Sridharan, 2015) delve deeper into mathematical models weighting differences such as consumer, service, recalls, warranty, end-of-use, end-of-life returns; however, this paper generalizes the variances for the purpose of an overall theoretical framework. Zhang, Cao, Min, and Wang, (2019) enter customer preference into reverse logistics also providing mathematical models. While Euchi, Bouzidi and Bouzidi (2019) further customer satisfaction identifying relationships as a key factor furthering the trust factor the theoretical models, trust, in particular, espoused in this paper.

Blockchain technology can be an enabler of a circular, economy, closed-loop supply chains and reverse logistics (Saberi Kouhizadeh, Sarkis, \& Shen, 2019; Zang, Cao, Min, \& Wang, 2019). Blockchain technology, with its inexpensive investments, can improve the entire logistics workflow for all parties involved in the logistics process including small companies. It can improve information flow fulfilling privacy, transparency and trust requirements. However, the positive impact of decreased transactional costs and customer trust afforded by Blockchain are magnified in reverse logistics over traditional forward chain logistics.

\section{CONCLUSION}

Werbach (2018) stated distributed ledgers broadly referred to in this paper as Blockchain is the first technology in twenty years to have similar impact potential as the internet; however, still in its infancy, success will be determined by technology advances, legal and governance challenges, and adoption. Perspectives to explain the potential for disruption on the supply chain industry by the added umbrella of security through decentralization and reliability were provided through the two theoretical model frameworks Transaction Cost Economics (TCE) theory and Social Exchange Theory (SET). TCE theory involves a transaction cost incurred in making an economic exchange, for example, costs required to come to an acceptable agreement with the other party to the transaction, drawing up an appropriate contract, etc. SET culminates the understanding of human social behavior in economic undertakings providing an examination of the inter-organizational exchange relationship between two firms. The use of Smart 
Contracts placed additional emphasis on the security of Blockchains in supplier customization leading to a heightened level of trust by all parties. Both the theoretical model frameworks and the supporting literature provide deep insight into Blockchain as the future technology innovation in the supply chain.

\section{IMPLICATIONS FOR FURTHER DISCUSSION}

Prediction of future waves of adoption can assist smaller companies to begin to move in the direction of the technology prior to being dictated to do so by larger transaction partners which could both add to the cost of overall business transactions and lesson the time for proper planning. Inclusion of the Diffusion of Innovation Theory which describes the benefits of early adoption Rodgers (1962) could add depth to the implications of this and future research. Additionally, future research will gather empirical data from industry experts to test, add, and potentially change the model for predicting industry technology adoption in this area. Finally, trust, cooperation, and reverse logistics were explored to explain how the security in Blockchain can be used for information sharing and will remain the focal points for future research. The future of trust is a compelling point of focus with the erosion of close relationships; however, the ability for technology to add this crucial element to transactional relationships is key to both innovation and industry growth.

\section{REFERENCES}

Anderson, J.C, \& Narus, J.A. (1990) A model of the distributor-manufacturer working relationships. Journal of Marketing, 54(1), 42-58.

Bambara, J. J., \& Allen, P. R. (2018). Blockchain a practical guide to developing business, law, and technology solutions. New York, NY: McGraw-Hill Education.

Borkovich, D. J., \& Breese-Vitelli, J. (2014). The Influence of mobile technology culture: Blind trust, naiveté, or skepticism?. Issues in Information Systems, 15(2), 399-410.

Borkovich, D. J., \& Breese, J. (2016). Social media implosion: Context collapse!. Issues in Information Systems, 17(4), 167-177.

Cachon, G., Fisher, M., (2000). Supply chain inventory management and the value of shared information. Management Science, 46(8), 1032-1048.

Casey, M., \& Vigna, P. (2018). The truth machine: The blockchain and the future of everything. New York, NY: HarperCollins.

Chen, I.J., Paulraj, A., Lado, A.A., (2004). Strategic purchasing, supply management and firm performance. Journal of Operations Management, 22(5), 505-523.

Devaraj, S., Vaidyanathan, G., \& Mishra, A. N. (2012). Effect of purchase volume flexibility and purchase mix flexibility on e-procurement performance: an analysis of two perspectives. Journal of Operations Management, 30(7-8), 509-520.

Doney, P.M., Cannon, J.P., (1997). An examination of the nature of trust in buyer-seller relationships. Journal of Marketing, 61, 35-51.

Doz, Y.L., (1996). The evolution of cooperation in strategic alliances: initial conditions or learning processes. Strategic Management Journal, 17, 55-83. 
Euchi, J., Bouzidi, D., \& Bouzidi, Z. (2019). Structural factors of acute success factors of performance of reverse logistics relative to customer satisfaction. International Journal of Combinatorial Optimization Problems and Informatics, 10(2), 39-56. Retrieved April 16, 2019.

Fabbri, D., \& Klapper, L.F. (2016). Bargaining power and trade credit. Journal of Corporate Finance, 41, 66-80.

FBI. (2019). Retrieved from https://www.fbi.gov/scams-and-safety/common-fraud-schemes/letter-of-credit-fraud on April 29, 2019.

Fettermann, D. d. C., \& Echeveste, M. E. S. (2014). New product development for mass customization: A systematic review. Production \& Manufacturing Research, 2(1), 266-290.

Fogliatto, F.S., Da Silveira, G.J. and Borenstein, D. (2012). The mass customization decade: an updated review of the literature. International Journal of Production Economics, 138(1), 14-25.

Gosain, S., Malhotra, A., El Sawy, O.A., (2005). Coordinating for flexibility in e-business supply chains. Journal of Management information Systems, 21(3), 7-46.

Guide, V. D., \& Wassenhove, L. N. (2009). OR FORUM-The Evolution of Closed-Loop Supply Chain Research. Operations Research, 57(1), 10-18.

Hackius, N., \& Petersen, M. (2017). Blockchain in logistics and supply chain: trick or treat?. In Proceedings of the Hamburg International Conference of Logistics (HICL) (3-18). epubli.

Handfield, R.B., Bechtel, C., (2002). The role of trust and relationship structure in improving supply chain responsiveness. Industrial Marketing Management, 31, 367-382.

House, R. J., Hanges, P. J., Javidan, M., Dorfman, P. W., \& Gupta, V. (Eds.). (2004). Culture, leadership, and organizations: The GLOBE study of 62 societies. Thousand Oaks, CA: Sage Publications.

Hsieh, Y., Chiu, H., Hsu, Y., (2008). Supplier market orientation and accommodation of the customer in different relationship phases. Industrial Marketing Management, 37, 380-393.

Hsu, C., Kannan, V.R., Tan, K., Leong, G.K., (2008). Information sharing, buyer-supplier relationships, and firm performance: a multi-region analysis. International Journal of Physical Distribution \& Logistics Management, 38(4), 296-310.

IBM (2017). Forward together: Three ways Blockchain explorers chart a new direction. IBM Institute for Business Value. Armonk, NY: IBM.

Jing, B. \& Seidmann, A. (2014). Finance sourcing in a supply chain. Decision Support Systems, 58, 15-20.

John, S. T., \& Sridharan, R. (2015). Effect of grading of product return on the network design of a reverse supply chain: A comparative study. International Journal of Applied Management Science, 7(2), 142.

John, S. T., Sridharan, R., \& Kumar, P. N. (2017). Reverse logistics network design: A case of mobile phones and digital cameras. The International Journal of Advanced Manufacturing Technology, 94(1-4), 615-631.

Kim, K.K., Umanath, N.S., Kim, B.H., (2005). An assessment of electronic information transfer in B2B supplychannel relationships. Journal of Management Systems, 22(3), 293-320.

Kokina, J., Mancha, R., \& Pachamanova, D. (2017). Blockchain: Emergent industry adoption and implications for accounting. Journal of Emerging Technologies in Accounting, 14(2), 91-100. 
Kollock, P., (1994). The emergence of exchange structures: an experimental study of uncertainty, commitment and trust. American Journal of Sociology, 100, 313-345.

Koul, S. (2018). Value Creation through Blockchain Technology in Supply Chain Management. Retrieved April 9, 2019, from https://www.omicsonline.org/open-access/value-creation-through-Blockchain-technology-insupply-chain-management-106883.html

Lajili, K., \& Mahoney, J.T. (2006). Revisiting agency and transaction costs theory predictions on vertical financial ownership and contracting: Electronic integration as an organizational form choice. Managerial Decision and Economics, 27(7), 573-586.

Lampel, J., \& Mintzberg, H. (1996). Customizing customization. Sloan Management Review, 38(1), 21-30.

Le Blanc, H.M., (2006). "Closing loops in supply chain management: Designing reverse supply chains for end-oflife vehicles," Other publications TiSEM f33876fe-e9a7-4c47-82a0-a, Tilburg University, School of Economics and Management.

Liang, T. P., \& Huang, J. S. (1998). An empirical study on consumer acceptance of products in electronic markets: a transaction cost model. Decision Support Systems, 24(1), 29-43.

Lo, S., \& Wang, J. C. (2014). Bitcoin as money?. Boston Federal Reserve, Current Policy Perspectives, 14(4).

Lorenz, E., (1988). Neither friends nor strangers: informal networks of subcontracting in French Industry. In: Gambetta, D. (Ed.), Trust: Making or Breaking Cooperative Relations, (pp. 194-210). Basil-Blackwell, New York, NY,

Malone, T.W., Yates, J. \& Benjamin, R.I. (1987). Electronic markets and electronic hierarchies. Communications of the ACM, 30(6), 484-497.

Mentzer, J.T, DeWitt, W., Keebler, J.S., Min, S., Nix, N.W., \& Smith, C.D. (2001). Defining supply chain management. Journal of Business Logistics, 22(2), 1-25.

Mian, S.L. \& Smith, Jr., C.W. (1992). Accounts receivable management policy: Theory and evidence. The Journal of Finance, 47(1), 169-200.

Morgan, R.M., and Hunt, S.D. (1994). The commitment-trust theory of relationship marketing. Journal of Marketing, 58(3), 20-38.

Rogers, E. M. (1962). Diffusion of innovations. New York, NY: Free Press of Glencoe.

Rosenzweig, E., Roth, A.V., Dean, J.W., (2003). The influence of an integration strategy on competitive capabilities and business performance: an exploratory study of consumer products manufacturers. Journal of Operations Management, 21(4), 437-456.

Saberi, S., Kouhizadeh, M., Sarkis, J., \& Shen, L. (2019). Blockchain technology and its relationships to sustainable supply chain management. International Journal of Production Research, 57(7), 2117-2135.

Seabright, M., Levinthal, M., Fichman, M., (1992). Role of individual attachments in the dissolution of interorganizational relationships. Academy of Management Journal, 35, 122-160.

Son, J. Y., Narasimhan, S., \& Riggins, F. J. (2005). Effects of relational factors and channel climate on EDI usage in the customer-supplier relationship. Journal of Management Information Systems, 22(1), 321-353. 


\section{Issues in Information Systems}

Volume 20, Issue 2, pp. 140-150, 2019

Szabo, N. (1996). Smart contracts: Building blocks for digital markets. Retrieved April 8, 2019, from http://www.alamut.com/subj/economics/nick_szabo/smartContracts.html

Tombido, L. L., Louw, L., \& Eeden, J. V. (2018). A systematic review of 3Pls' entry into reverse logistics. South African Journal of Industrial Engineering, 29(3), 235-260.

Tapscot, A., \& Tapscot, D. (2017). How blockchain is changing finance. Harvard Business Review. Retrieved March 1, 2017, from https://hbr.org/2017/03/how-blockchain-is-changing-finance.

Tapscott, D., \& Tapscott, A. (2016). Blockchain revolution: How the technology behind bitcoin is changing money, business, and the world. Toronto: Portfolio/Penguin.

Werbach, K. (2018). The Blockchain and the New Architecture of Trust. Cambridge, MA: MIT Press.

Yang, S.A. \& Birge, J.R. (2018). Trade credit, risk sharing, and inventory financing portfolio. Management Science, 64(8), 3667-3689.

Young-Ybarra, C., Wiersema, M., (1999). Strategic flexibility in information technology alliances: the influence of transaction cost economics and social exchange theory. Organization Science, 10(4), 439-459.

Zhang, C., Cao, Z., Min, J., \& Wang, M. (2019). Production and pricing strategy of closed-loop supply chain based on customer preference. Engineering Letters, 27, 194-201. Retrieved April 16, 2019. 